JFC

21,1

84

\section{Detection and prevention of financial abuse against elders}

\author{
Priscilla A. Harries, Miranda L. Davies, Kenneth J. Gilhooly,
} Mary L.M. Gilhooly and Deborah Cairns

School of Health Sciences and Social Care, Brunel Institute for Ageing Studies, Brunel University, Uxbridge, UK

\begin{abstract}
Purpose - This paper reports on banking and finance professionals' decision making in the context of elder financial abuse. The aim was to identify the case features that influence when abuse is identified and when action is taken.

Design/methodology/approach - Banking and finance professionals $(n=70)$ were shown 35 financial abuse case scenarios and were asked to judge how certain they were that the older person was being abused and the likelihood of taking action.

Findings - Three case features significantly influenced certainty of financial abuse: the nature of the financial problem presented, the older person's level of mental capacity and who was in charge of the client's money. In cases where the older person was more confused and forgetful, there was increased suspicion that financial abuse was taking place. Finance professionals were less certain that financial abuse was occurring if the older person was in charge of his or her own finances.

Originality/value - The research findings have been used to develop freely available online training resources to promote professionals' decision making capacity (www.elderfinancialabuse.co.uk). The resources have been advocated for use by Building Societies Association as well as CIFAS, the UK's Fraud Prevention Service.
\end{abstract}

Keywords Decision making, UK, Banking professionals, Factorial survey design, Online training, Web site training, Elder financial abuse

Paper type Research paper

\section{Introduction}

Everybody - but particularly older adults - can be targeted by conmen and rogue traders. These problems are well documented and well known to law enforcement bodies such as the Police and Trading Standards (British Banking Association, 2010, p. 1).

(C) [The authors]

This article is published under the Creative Commons Attribution (CC BY 3.0) licence. Anyone may reproduce, distribute, translate and create derivative works of this article (for both commercial and non-commercial purposes), subject to full attribution to the original publication and authors. The full terms of this licence may be seen at http://creativecommons.org/licences/ by/3.0/legalcode. The research reported here was funded by the UK cross council New Dynamics of Ageing Programme, ESRC Reference No. RES-352-25-0026, with Mary L.M. Gilhooly as Principal Investigator. Web-based training tools, developed from the research findings, were subsequently funded by the ESRC follow-on fund ES/J001155/1 with Priscilla A. Harries as Principal Investigator. The views in this article are those of the authors and do not necessarily represent the New Dynamics of Ageing Programme or the ESRC. The funders selected the proposals for funding following competitive peer review and have supported open access to the \begin{abstract}
project data through the ESRC UK data archive.
\end{abstract}
Journal of Financial Crime Vol. 21 No. 1, 2014 pp. 84-99

Emerald Group Publishing Limited 1359-0790

DOI 10.1108/JFC-05-2013-0040 
Elder financial abuse is defined in the England and Northern Ireland adult safeguarding policy guidance No Secrets (Department of Health (DH, 2000)), as "theft, fraud, exploitation, pressure in connection with wills, property or inheritance or financial transactions, or the misuse or misappropriation of property, possessions or benefits (DH, 2000, p. 9)". Research has shown that 0.66 per cent of older people in the UK have experienced financial abuse by a close friend, relative or carer (O’Keefe et al., 2007). Add to this people who are victims of scams, rogue workmen and plausible sales people (British Banking Association, 2010) and those in care, for example with severe dementia, who are recognised to be at greater risk (Alzheimer's Society, 2011). The detrimental effects of financial crime are significant; the psychological impacts of financial abuse have been equated to being a victim of violent crime (Deem, 2000) and yearly fraud loss has been calculated at £38.4 billion per year in the UK (Social Care Institute for Excellence, City of London Police and National Fraud Intelligence Bureau, 2011). Financial crime is therefore an increasing problem for the economy (Social Care Institute for Excellence, City of London Police and National Fraud Intelligence Bureau, 2011).

Agencies are intensifying their efforts to detect and prevent financial crimes with a plethora of reports, advice and guidance being issued by such organisations as Operation Sterling (Economic and Specialist Crime Prevention Team, Metropolitan Police), the British Bankers Association (BBA), the Building Societies Association (BSA), the Centre for Policy on Ageing, and charities such as the Alzheimer's Society, Age UK, and Action on Elder Abuse. However, what has been called for, by the Centre for Policy on Ageing (2008) is training for health, social care, police, legal and financial professionals to enhance professionals' capacity to recognise and prevent financial elder abuse.

Financial crimes against elders, also termed elder financial abuse, currently constitute approximately 25 per cent of safeguarding referrals in England (Social Care Institute for Excellence, City of London Police and National Fraud Intelligence Bureau, 2011). Although health and social care professionals are well placed to identify financial abuse of those with whom they have regular contact as well as having procedures for safeguarding vunerable adults, the financial sector's involvement has been highlighted as vital (Mulroy and O'Neill, 2011). Given the access finance professionals have to customer's financial information, they play a key role in terms of identifying elder financial abuse at an early stage, thereby enabling action to be taken before money or assets are lost (Wilson et al., 2009). Although the Data Protection Act (1998) relates to the need to protect the confidentiality of clients' account data, this duty is not absolute: an exemption is in place (Section 29) that allows data to be shared in order to detect or prevent a crime. Although consent to share information from the client should be sought as part of good practice this is not a pre-requisite to sharing information with such parties as the police, trading standards or social care services (Social Care Institute for Excellence, City of London Police and National Fraud Intelligence Bureau, 2011). Banking and finance professionals are being encouraged to be more proactive in order to reduce abuse (CIFAS, 2012). Training is needed to support the development professional decision making in this domain of expertise. Such training needs to be underpinned by research in order for it to be evidence based.

\section{Literature review}

In Australia, Lowndes et al. (2009) conducted a literature review as part of the protecting elder's assets study, which covered issues related to the definition of elder

\section{Financial abuse against elders}

85 
$\mathrm{JFC}$

21,1

86

financial abuse, what constitutes such abuse and what can be done about it. This included discussion of the involvement of the banking and financial services sector in addressing elder financial abuse. This was followed by a very comprehensive review of the literature which was published by Fealy et al. (2012): they reviewed 53 reports and research studies in order to examine the definitions of elder financial abuse, the prevalence and impact of elder financial abuse, victims and perpetrator profiles and risk factors of financial abuse as well as strategies for detecting, preventing and managing elder financial abuse. In their conclusions they stated that banking and finance professionals are well placed to review and evaluate measures aimed at detecting and preventing elder financial abuse and that strategies developed to do so need to be based on reliable evidence.

In terms of empirical studies that have been undertaken, data from the case files of the New York adult protective services program were studied to identify risk factors associated with financial exploitation of and mismanagement by elders (Choi et al., 1999). Cognitive impairment was found to be a key risk factor and those who lived and owned their own homes were especially vulnerable to financial exploitation. The researchers drew attention to the important point that with the increasing older person population, the problems are likely to become more prevalent in the future. They called for more empirical research to be undertaken to provide data to support the development of preventive interventions. The potential for banking and finance professionals to detect abuse when they deal with older customers has been highlighted as a concluding point of the USA National Elder Abuse Incident Study report (National Centre on Elder Abuse, 1998). They called for ways in which bank staff could be supported to identify and report cases of suspected elder financial abuse.

The National Elder Abuse Incidence Study (NEAIS) in America (National Centre on Elder Abuse, 1998), included detection and reporting of elder abuse by banking professionals as part of their research. This was challenging to conduct as only 30 per cent of banks approached to participate gave their approval for staff involvement. Reasons for refusal included senior staff not giving their agreement for staff participation, and legal representation advising to decline to participate. The report did not provide a breakdown of how many of the cases of elder abuse identified were made specifically by banking professionals in relation to elder financial abuse, but referrals from banking staff represented 0.4 per cent of all reports substantiated by adult protective services. In the USA the focus is predominantly on training guidance for banking staff about elder financial abuse. For example, Kaye and Darling (2000) reported that in the state of Oregon, every bank was sent a training pack about elder financial abuse. This included a video of potential financial abuse scenarios, information about the sorts of circumstances that should lead to referral to other agencies, and information cards for cashiers to have at the cash desk. The training emphasis is perhaps related to the fact that in the some states of the USA such as California, banking staff are legally obliged to report suspected elder financial abuse (Office of Governor, 2009). However, how much of the training information is underpinned by research evidence is not clear.

Arksey et al. (2008) conducted interviews with 12 professionals in England who had experience advising on financial management for older people. The professionals were asked questions about the sorts of financial support carers were giving, and common problems that emerged. They reported that families had different ideas about what sorts of behaviour was acceptable in terms of dealing with money, and that potential abuse 
sometimes only emerged when family members were critical of financial decisions made by other family members.

In terms of guidance for banking professionals in the UK, the BBA response to the No Secrets review highlighted concerns that there were no specific practice guidelines relating to financial abuse for the financial services sector (DH, 2008). Although useful survey data has been collected on the types of fraud that occur in the finance sector and the demographics of those targeted (CIFAS, 2012), there is still a need to share best practice in detection and prevention of elder financial abuse.

There is limited literature addressing the issue of elder financial abuse and the role of banking and finance professionals in abuse detection. There appears to be no evidence of a UK based research project examining the factors that have the most influence on banking and finance professionals' decision making when detecting and preventing financial abuse of older customers. This paper fulfils the call to look specifically at how professionals in financial services can help to reduce elder financial abuse (Crosby et al., 2008). It is important to consider how cues or factors (case features) influence banking and finance professionals to detect and prevent financial elder abuse. If this information is identified it can be used to develop training and guidance for banking and finance professionals in terms of providing research evidence as to how these factors these factors should influence detection and preventative action.

Aims

The research aimed to identify which cues or factors have the greatest influence on decision making by finance professionals in cases of elder financial abuse. The research questions were as follows:

$R Q 1$. Which factors explain banking and finance professionals' certainty that elder financial abuse is taking place?

$R Q 2$. Which factors explain banking and finance professionals' likelihood of taking action in cases of suspected elder financial abuse?

\section{Research design}

Applying the factorial survey approach, professionals were shown a series of elder financial abuse case scenarios on a web site developed for the project, and were asked to make judgements. The factorial survey approach measures the relationship between information contained in the case scenarios and the judgements that are made (Rossi and Nock, 1982).

\section{Development of the case scenarios}

In-depth interviews were conducted with banking and finance professionals $(n=20)$ (e.g. branch managers, cashiers, and financial crime investigators) using the critical incident technique (CIT) (Flanagan, 1954). Participants were asked about their experiences of detecting financial abuse of an older customer in order to establish the key factors or cues that lead to abuse being suspected. Further details of the methods for eliciting cues are given in Davies et al. (2011). Three key cues of abuse were identified: the "identifier of the abuse", the nature of the "financial problem suspected", and "who is in charge of the money" (Gilhooly et al., 2013). In order to make the case scenarios representative of the sorts of information that finance professionals might have available to them, additional

\section{Financial abuse against elders}


JFC

21,1

\section{8}

information was required: age, gender, and an indication of the older person's physical and mental capacity were added following the recommendations of the project advisory board (experienced finance professionals from a major UK bank and representatives from the Building Society Association, representatives from Age UK, Alzheimer's Society, Operation Sterling, Action on Elder Abuse, College of Occupational Therapists, North Tyneside Council Social Care and Rosemead G.P. Surgery). In total seven cues were included in the case scenarios presented to banking and finance professionals, as shown in Table I.

\section{Independent variables}

See Table I

\section{Fractional factorial design}

The case scenarios presented to participants were created by using a fractional factorial design, whereby all participants viewed a single set, with overall presentation of the seven cue levels being both symmetrical and orthogonal (Dülmer, 2007). Using SPSS Version 15.0, author KG generated a set of 35 cases. N.B. Blank cue levels were included for the "identifier of abuse", and "financial problem suspected" cues as a point of comparison, to measure the judgements made by professionals with minimal information present (Taylor, 2006).

Figure 1 provides an example of a case scenario presented to finance professionals.

\begin{tabular}{ll} 
Cue & Cue levels \\
\hline Age (years) & $66,76,86,96$ \\
Gender & Male, female \\
Identifier of abuse & You notice \\
& A family member tells you \\
& A carer tells you \\
& Another member of staff tells you \\
& Blank
\end{tabular}

Financial problem suspected

A relative concerned about loss of inheritance: "a relative has objected to the house being sold to pay for her care needs because of the impact on inheritance"

Third party manipulation: "a third party who visits the bank with this older person seems to be manipulating him/her"

Overseas cash prize: "this older person has been asked to transfer money into an overseas bank account to claim a cash prize" Overdrawn account: "this older person's bank account is overdrawn and he/she does not know why"

Out of ordinary cash withdrawal: "this older person's cash withdrawal was out of the ordinary for his/her routine" Blank

Physical capacity

Mental capacity

Table I.

Who is in charge of money

Elder financial

abuse cues
No physical health problems/minor physical health problems/ major physical health problems

Fully mentally aware/at times slightly confused/extremely confused forgetful In charge of their own money Third party signatory A holder of a lasting power of attorney 


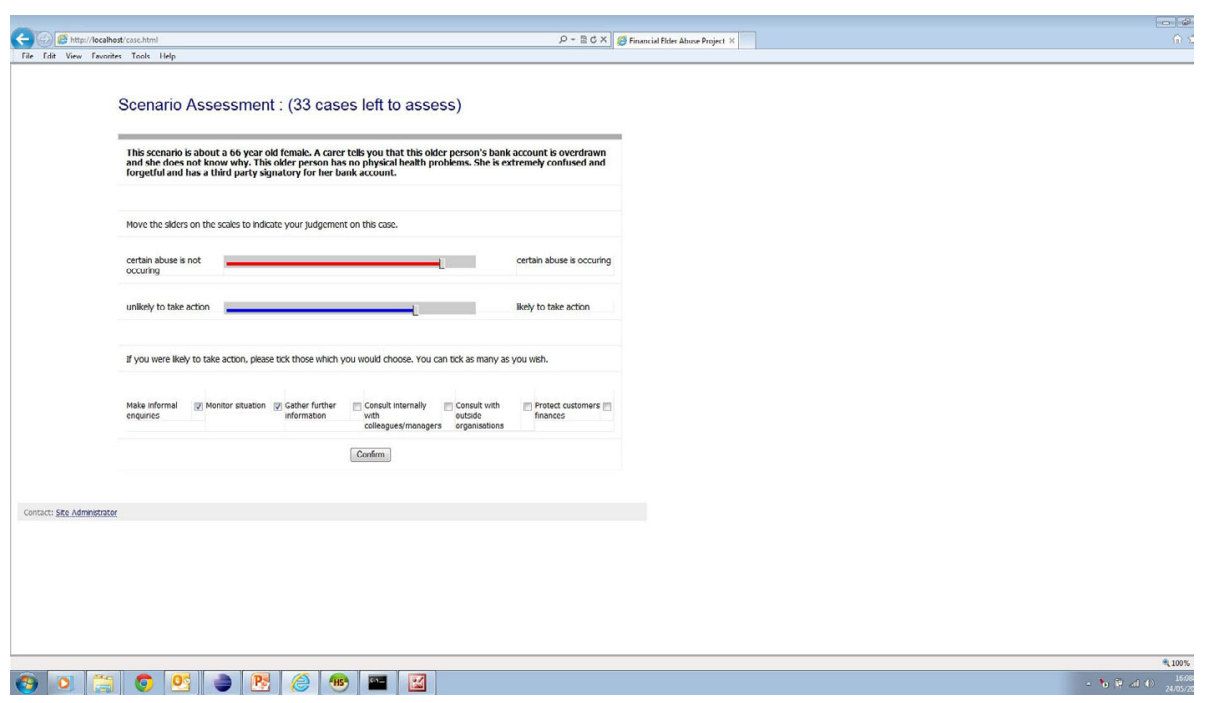

\section{Dependent variables}

Participants were asked to make two judgements in response to each scenario. This included first, their level of certainty of financial abuse (scale ranging from "certain abuse is not occurring" to "certain abuse is occurring"), and second, the likelihood that they would take action (ranging from "unlikely to take action" to "likely to take action"). Both judgements were represented on a "0-100" scale. In addition participants were asked to identify what actions they might take; the analysis of this third type of data will be reported separately.

\section{Sample}

Seventy banking and finance professionals completed the judgement task. Recruitment of banking professionals was assisted by a partner on the project consultation board who worked for a major UK bank. Recruitment information leaflets were administered to branch managers across North West London, South East London, and the Counties of Kent, Hampshire and Medway. The aim was to achieve coverage across inner city, suburban and rural areas. Finance professionals were recruited across the UK via the BSA. Demographic characteristics of the participant sample are reviewed in Table II. Participant job-roles included "branch/bank manager" $(n=30)$, "cashier/customer advisor" $(n=10)$, "banking management level professional" $(n=24)$, and "financial crime manager/investigator" $(n=6)$.

\begin{tabular}{lccr}
\hline Demographics & M & SD & Range \\
\hline Age (years) & 33.24 & 8.97 & $22-57$ \\
Years in current job role & 4.24 & 3.57 & $0-13$ \\
Years in profession & 9.71 & 8.72 & $0-33$ \\
Gender (\% female) & 71 & &
\end{tabular}

\section{Financial abuse against elders}

Figure 1. Example of case scenario 
JFC
21,1

90
Ethical approval

Ethical approval for the research was obtained from Brunel University research ethics committee.

\section{Procedure}

There were no formal participant exclusion criteria. The recruitment information highlighted that any banking or finance professional with an interest in the research topic of elder financial abuse was welcome to participate. Professionals who accessed the task web site were given two test case scenarios to judge prior to beginning the full scenario set of 35 elder financial abuse case scenarios with cases presented in a randomised order to each participant. The task took an average (median) of 19 minutes to complete. After finishing the task, participants were given further information about the purpose of the research, and were emailed a $£ 20$ Amazon online gift-voucher honorarium.

\section{Analysis}

To assess if there was a relationship between judgements of certainty of abuse and likelihood of taking action, a Pearson's correlation between the two measures was calculated. In order to determine the extent to which banking and finance professionals' judgements of certainty of elder financial abuse and likelihood of action being taken could be predicted based on elder financial abuse cues, multiple regression analysis was conducted.

Regression analysis was initially conducted for each participant's $(n=70)$ certainty of abuse and likelihood of action judgements, using the scenario cues as the independent or predictor variables. Scenarios with blank cue level information for "identifier of abuse" and "financial problem suspected" $(n=4)$ were excluded from the analysis because of the perfect co linearity between instances of blank cue levels for the two variables. Analysis was therefore conducted on certainty and likelihood scores for 31 scenarios. Regression analysis then took place at a group level using the elder financial abuse cues to predict the average certainty of abuse and likelihood of action across the group overall.

Three of the cues, identified as significant through the regression analysis, which were the "identifier of the abuse", the nature of the "financial problem suspected", and "who is in charge of the money", were recoded into dummy variables whereby each cue category becomes an independent variable, coded as either " 1 " or "0", representing if the category was present in the scenario. One cue level is chosen as a reference category and is excluded from the analysis (Cooksey, 1996). This then becomes the point of comparison for the different dummy variable categories (Hardy, 1993). The reference categories are identified in the reporting of the results. The dummy variable cues were entered into the regression applying a block wise entry.

In order to determine the relative influence of each cue on certainty of abuse and likelihood of action judgements, incremental $F$-tests were conducted to test if the variance in judgement attributable to each cue as a whole was statistically significant. For instance, looking at the overall effect of the financial problem suspected rather than comparing each type of financial problem. This involved re-running the regression analysis excluding each elder financial abuse cue (or set of dummy variables) in turn to identify the change in $R^{2}$ that could be attributable to each cue. Prior to running regression analysis a histogram of the standardized residuals for average certainty of abuse and likelihood of action judgements across the participants determined a normal distribution of scores for both measures (Cooksey, 1996). 


\section{Results}

Descriptive judgement characteristics

Table III provides the descriptive characteristics of average certainty of abuse and likelihood of action scores for the finance professionals $(n=70)$ in response to the elder financial abuse case scenarios.

A strong positive relationship was found between judgements of certainty of abuse and likelihood of action in cases of suspected elder financial abuse $(r=0.98, n=35$, $p<0.001$ ) with actions responses being generally higher than certainty responses. A paired samples $t$-test identified a significant difference between average certainty of abuse $(\mathrm{M}=56.10, \mathrm{SE}=3.37)$ and likelihood of action $(\mathrm{M}=63.24$, $\mathrm{SE}=3.38),(t(34)=-10.75, p<0.001, r=0.77)$. It therefore seems that although certainty and likelihood were positively related, participant's likelihood of taking action in response to a situation tended to be higher than their degree of certainty that elder financial abuse was taking place.

Which factors explain banking and finance professionals' certainty that elder financial abuse is taking place?

The professional participants used an average of three statistically significant cues to judge certainty of abuse, with a range from 0 to $7 . R^{2}$ ranged from 21 to 97 per cent, with a mean of 79 per cent. An average of three statistically significant cues was also used to determine likelihood of action being taken, with a range from 0 to $9 . R^{2}$ for likelihood of action ranged from 43 to 95 per cent, with a mean of 77 per cent.

Regression analysis was conducted at a group level using the scenario cue information to predict the average certainty of abuse for the banking and finance professionals $(n=67)$. $N$-sizes did not total 70 , as three participants had not given serious attention to the task, shown by giving certainty of abuse in each scenario as 50 . Table IV provides the results from the final model of the regression analysis.

The results show a significant impact of all four categories of financial problem suspected, as well as different options for who is in charge of the money, and the older person's mental capacity. In addition, where the identifier of the abuse was a family member a significant influence on judgements was evident.

The quantitative cue mental capacity can be interpreted as showing that if all the other scenario cues are controlled, with each increase in mental capacity concerns (e.g. changing from at times slightly confused, to extremely confused and forgetful), certainty of abuse increases by 8 per cent. The dummy variables show the difference between each category versus the reference group, again controlling for all the additional cues. For instance, for financial problems involving an overseas cash prize, certainty of abuse is 31 per cent higher than for cases involving an out of ordinary transaction (the reference group) if all the other cues are controlled.

\begin{tabular}{lllr}
\hline Judgement & M & SD & Range \\
\hline Certainty of elder financial abuse (\%) & 56 & 20 & $15-85$ \\
Likelihood of action being taken (\%) & 63 & 20 & $14-89$
\end{tabular}

Note: Scenario total $n=35$

Financial abuse against elders

91

Table III.

Mean, SD and range of certainty of abuse and likelihood of action scores (scale 0-100 with 0 as low score and 100 as high score) 
$\mathrm{JFC}$
21,1

Table IV.

Regression analysis to predict average certainty of abuse for the banking and finance professionals

\begin{tabular}{llrrr}
\hline & & & SE & $p$ - \\
Cue (reference category) & Category & B & B & value \\
\hline Constant & & 32.38 & 3.48 & 0.00 \\
Age & & -0.01 & 0.04 & 0.81 \\
Gender & Male & -1.30 & 0.83 & 0.14 \\
Identifier of abuse (You) & Staff member & -1.60 & 1.15 & 0.18 \\
& Family & -3.85 & 1.16 & 0.00 \\
Financial problem suspected (out of & -1.87 & 1.22 & 0.14 \\
ordinary cash withdrawal) & Carer & 24.51 & 1.52 & 0.00 \\
& Third party manipulation & 11.45 & 1.43 & 0.00 \\
& A relative concerned about loss of & & & \\
& inheritance & 30.64 & 1.30 & 0.00 \\
Who is in charge of the money (in charge & Third party signatory & -3.59 & 1.30 & 0.01 \\
of own money) & Overseas cash prize & 6.74 & 1.03 & 0.00 \\
Physical capacity & Lasting power of attorney & 4.58 & 1.07 & 0.00 \\
Mental capacity & & 1.03 & 0.54 & 0.08 \\
& & 7.64 & 0.53 & 0.00
\end{tabular}

Notes: $R^{2}=0.99(p<0.001) ; n=67$; reference category is given in brackets in the first column

In order to determine the relative influence of each cue on certainty judgements, incremental $F$-tests were conducted, with the results presented in Table V. This tests if the variance in judgements attributable to each cue as a whole is statistically significant. Conclusions could then be drawn about the degree to which professionals' decisions were influenced by each cue.

The $R^{2}$ change (or squared semi-partial correlation) value represents the difference between each model's $R^{2}$, and the $R^{2}$ for the overall regression model, which was 99 per cent. The $F$-test identifies if the difference between the overall model and the model excluding each variable is significant. $F$-test results indicate that the nature of the financial problem suspected, the older person's mental capacity and who is in charge of the money explain a significant amount of the variance in certainty of abuse scores.

The nature of the relationship between mental capacity and certainty of abuse can be seen from the overall regression analysis (as mental capacity deteriorates certainty of abuse increases). $t$-tests of the regression coefficients were conducted to consider the relative impact of the dummy variables representing the nature of the financial

\begin{tabular}{lcc}
\hline Cue & $R^{2}$ change & $F$ \\
\hline Age & 0.00 & 0.058 \\
Gender & 0.00 & 2.435 \\
Identifier of abuse & 0.01 & 3.698 \\
Financial problem suspected & 0.78 & $295.659^{*}$ \\
Who is in charge of the money & 0.03 & $22.970^{*}$ \\
Physical capacity & 0.00 & 3.577 \\
Mental capacity & 0.14 & $205.724^{*}$
\end{tabular}

Note: Significant at: ${ }^{*} p<0.001$
Table V.

$R^{2}$ change and $F$-test results for each elder financial abuse cue predicting professionals' certainty of abuse 
problem suspected and who is in charge of the money. For instance, is certainty of abuse higher where cases involve one type of financial problem versus another? Applying the Bonferroni correction, a revised significance level of 0.005 was used to minimise the Type I error rate associated with running multiple $t$-test comparisons (Field, 2009).

Cases involving an out of ordinary cash withdrawal had significantly lower certainty of abuse than cases involving third party manipulation $(\mathrm{B}=-24.51, \mathrm{SE} \mathrm{B}=1.52)$, $t(17)=-16.14, p<0.001, r=0.97$; suspected abuse by relatives to protect inheritance $(\mathrm{B}=-11.45, \mathrm{SE} \mathrm{B}=1.43), t(17)=-8.00, p<0.001, r=0.89$; and winning an overseas cash prize $(\mathrm{B}=-30.64, \mathrm{SE} \mathrm{B}=1.30), t(17)=-23.64, p<0.001, r=0.99$. There was no significant difference between certainty of abuse where cases involved an out of ordinary cash withdrawal versus an overdrawn account, $t(17)=-2.76$, NS, $r=0.54$.

Cases involving an overdrawn bank account had a significantly lower certainty of abuse than cases involving third party manipulation $(B=-28.09, \mathrm{SE} B=1.38)$, $t(17)=-20.36, p<0.001, r=0.98$; suspected abuse by relatives to protect inheritance $(\mathrm{B}=-15.04$, SE $\mathrm{B}=1.31), t(17)=-11.53, p<0.001, r=0.94$; and winning an overseas cash prize $(\mathrm{B}=-34.23$, $\mathrm{SE} \mathrm{B}=1.13), t(17)=-30.28, p<0.001, r=0.99$. Cases involving suspected abuse by relatives to protect inheritance had a significantly lower certainty of abuse than cases involving third party manipulation $(B=-13.06$, $\mathrm{SE} \mathrm{B}=1.52), t(17)=-8.58, p<0.001, r=0.90$.

Cases involving winning an overseas cash prize had a significantly higher certainty of abuse than cases involving third party manipulation $(B=6.14$, SE $B=1.37)$, $t(17)=4.48, p<0.001, r=0.74$; and suspected abuse by relatives to protect inheritance $(\mathrm{B}=19.19$, $\mathrm{SE} \mathrm{B}=1.30), t(17)=14.77, p<0.001, r=0.96$.

$t$-tests of the regression coefficients were also conducted to explore certainty of abuse for the different categories of who was in charge of the older person's money. Certainty of abuse was significantly higher where there was a third party signatory in charge of the money rather than the older person themselves $(\mathrm{B}=6.74$, $\mathrm{SE} \mathrm{B}=1.03)$; $t(17)=6.52, p<0.001, r=0.85$. Certainty of abuse was also significantly higher where a holder of lasting power of attorney was in charge of the finances rather than the older person $(\mathrm{B}=4.58$, $\mathrm{SE} \mathrm{B}=1.07) ; t(17)=4.30, p<0.001, r=0.72$. There was no significant difference between professionals certainty of abuse where third party signatories were in charge of the money compared to where a holder of lasting power of attorney was in control; $t(17)=1.87$, NS, $r=0.41$.

\section{Which factors explain banking and finance professionals' likelihood of taking action in} cases of suspected elder financial abuse?

The results of multiple regression analysis to predict the finance professionals' average likelihood of taking action are reported in Table VI.

The results show a significant impact of all categories of the financial problem suspected cue except for "overdrawn account". In addition, the "who is in charge of the money" dummy variables and the older person's "mental capacity" were significant. If all the other scenario cues are controlled, with each increase in mental capacity concerns, likelihood of action increases by 8 per cent. The dummy variables show the difference between each category versus the reference group, again controlling for all the additional cues. For instance, for financial problems involving an overseas cash prize,
Financial abuse against elders

93 
JFC
21,1

94

\begin{tabular}{llrrr}
\hline & & & SE & $p$ - \\
Cue (reference category) & Category & B & B & value \\
\hline Constant & & 39.525 & 4.47 & 0.00 \\
Age & & 0.004 & 0.05 & 0.94 \\
Gender & Male & -1.115 & 1.07 & 0.31 \\
Identifier of abuse (You) & Staff member & -2.120 & 1.48 & 0.17 \\
& Family & -2.911 & 1.49 & 0.07 \\
Financial problem suspected (out of & Carer & -0.669 & 1.56 & 0.67 \\
ordinary cash withdrawal) & Third party manipulation & 21.006 & 1.95 & 0.00 \\
& A relative concerned about loss of & 5.052 & 1.84 & 0.01 \\
& inheritance & & & \\
& Overseas cash prize & 26.231 & 1.66 & 0.00 \\
Who is in charge of the money (in charge & Overdrawn account & -1.488 & 1.67 & 0.39 \\
of their own money) & Third party signatory & 6.417 & 1.33 & 0.00 \\
Physical capacity & Lasting power of attorney & 3.627 & 1.37 & 0.02 \\
Mental capacity & & 1.350 & 0.70 & 0.07 \\
& & 8.276 & 0.68 & 0.00
\end{tabular}

Table VI.

Regression analysis to predict likelihood of action by the banking and finance professionals

Notes: $R^{2}=0.98(p<0.001) ; n=65$

likelihood of action is 26 per cent higher than for cases involving an out of ordinary transaction (the reference group) if all the other cues are controlled.

To compare the overall impact of each cue, incremental $F$-tests were conducted, mirroring the process outlined when exploring the influence of the elder financial abuse cues on certainty of abuse. The results are shown in Table VII.

The $F$-test results indicate that again, the nature of the financial problem suspected, who is in charge of the money, and the older person's mental capacity explain a significant amount of the variance in likelihood of action scores.

The relationship between mental capacity and likelihood of action can be seen from the regression analysis (as mental capacity deteriorates likelihood of action increases). $t$-tests of the regression coefficients were conducted to explore the relationship between likelihood of action and the different categories of financial problem suspected.

Cases involving an out of ordinary cash withdrawal had significantly lower likelihood of action than cases involving third party manipulation $(B=-21.01$, $\mathrm{SE} B=1.95), t(17)=-10.77, p<0.001, r=0.93$; and winning an overseas cash prize $(\mathrm{B}=-26.23$, $\mathrm{SE} \mathrm{B}=1.66), t(17)=-15.76, p<0.001, r=0.96$.

\begin{tabular}{lcc}
\hline Cue & $R^{2}$ change & $F$-test \\
\hline Age & 0.00 & 0.006 \\
Gender & 0.00 & 1.085 \\
Identifier of abuse & 0.01 & 1.501 \\
Financial problem suspected & 0.71 & $125.885^{* *}$ \\
Who is in charge of the money & 0.03 & $12.003^{*}$ \\
Physical health & 0.01 & 3.744 \\
Mental capacity & 0.21 & $146.520^{* *}$
\end{tabular}

Note: Significant at: ${ }^{*} p<0.01$ and ${ }^{* *} p<0.001$
Table VII.

$R^{2}$ change and $F$-test results for each elder financial abuse cue predicting professionals' likelihood of taking action 
Cases involving an overdrawn bank account had a significantly lower likelihood of action than cases involving third party manipulation $(B=-22.50, \mathrm{SE} B=1.77)$, $t(17)=-12.70, p<0.001, r=0.94$; suspected abuse by relatives to protect inheritance $(\mathrm{B}=-6.54$, $\mathrm{SE} \mathrm{B}=1.68), t(17)=-3.91, p<0.001, r=0.62$; and winning an overseas cash prize $(\mathrm{B}=-27.72$, $\mathrm{SE} \mathrm{B}=1.45), t(17)=-19.10, p<0.001, r=0.97$.

Cases involving suspected abuse by relatives to protect inheritance had a significantly lower likelihood of action than cases involving third party manipulation $(\mathrm{B}=-15.95$, SE $\mathrm{B}=1.95), t(17)=-8.17, p<0.001, r=0.81$. Cases involving winning an overseas cash prize had a significantly higher likelihood of action than cases involving suspected abuse by relatives to protect inheritance $(\mathrm{B}=21.18, \mathrm{SE}$ $\mathrm{B}=1.67), t(17)=12.70, p<0.001, r=0.92$.

$t$-tests were also conducted to explore likelihood of action where different individuals were in charge of the older person's money. The likelihood of action being taken was significantly higher where there was a third party signatory in charge of the account in comparison to where the older person was in charge of their own finances $(\mathrm{B}=6.42, \mathrm{SE} \mathrm{B}=1.33), t(17)=4.84, p<0.001, r=0.76$. Likelihood of action was also significantly higher where a lasting power of attorney was in charge of the finances rather than the older person themselves $(\mathrm{B}=3.63, \mathrm{SE} \mathrm{B}=1.37) ; t(17)=2.65, p=0.02$, $r=0.54$. There was no significant difference between professionals likelihood of action where a third party signatory was compared to cases under a lasting power of attorney; $t(17)=1.89$, NS, $r=0.42$.

\section{Discussion}

Analysis of banking professionals' judgements of elder financial abuse case scenarios showed that certainty of abuse and likelihood of action were positively correlated, but likelihood of action was significantly higher than professionals' level of certainty of abuse. This could mean that sometimes professionals take action even when they are uncertain that abuse is taking place. This finding is interesting when considered in the context of false accusations of abuse; if professionals take action despite not being certain that financial abuse is occurring this does not effectively protect those who are falsely accused. For banking professionals, the emphasis on taking action may reflect the need to be seen to respond to suspected abuse due to the implications for the financial institutions: if fraudulent activity is identified there is a reduction in terms of lost revenue and potential liability. On the positive side, it is probably better that a situation of suspected abuse is investigated even if it proves to be not to be the case rather than action not being taken when abuse is occurring.

Three cues were found to have a significant influence on judgements of certainty of abuse and likelihood of action being taken by banking and finance professionals. These were the same three cues that had been identified through the critical incident interviews (Gilhooly et al., 2013), thereby indicating that the critical incidents had been an effective method of illciting key cues. These included the nature of the financial problem suspected, the older person's mental capacity and who was in charge of the individual's money. However, what was not known from the critical incident analysis was how these three factors related to judgements of certainty or action nor how they related to each other, i.e. how they might be weighted and combined with each other.

The pattern of findings was similar for judgements of certainty of abuse and likelihood of action, but the independent impact of mental capacity was higher on
Financial abuse against elders

95 
$\mathrm{JFC}$

21,1

96

professionals' judgements of likelihood of action. Where mental capacity was of concern, action was more likely to be taken. Overall, the nature of the financial problem suspected had the greatest influence on banking and finance professionals' judgements. This is perhaps a result of the focus of the finance professionals' role in the customer's financial management. Cases involving winning an overseas cash prize had significantly higher certainty of abuse than other categories such as an out of ordinary cash withdrawal or an overdrawn account. It is interesting that the financial problems where certainty of abuse was rated as significantly lower than others were those where the extent of financial losses were lower. For instance, a cash withdrawal that was out of the ordinary for the customer's routine was likely to involve less financial loss than where a relative has objected to the customer's house being sold.

Professionals' attention to whom is in charge of the older person's money may be expected given that it has been suggested that where an individual is not in charge of their own finances, the opportunities for elder financial abuse are increased (Edmonds and Noble, 2008; Wilson et al., 2009). This observation is supported by the fact that there was no significant difference between certainty of abuse where the individual was under a lasting power of attorney in comparison to a third party signatory (i.e. someone in charge other than the individual themselves). In both instances, certainty of abuse (and likelihood of action) was higher than where the individual was in independent control of their finances.

The findings of the research draws parallels with other research reports in terms of highlighting potential risks associated with who is in charge of the money. In research undertaken in Australia, Edmonds and Noble (2008) identified that circumstances where an older customer is no longer in charge of managing their own finances can allow for opportunities of financial abuse. If the bank account has a third party signatory or is managed under a power of attorney, there can be issues as to whether transactions reflect the customer's wishes.

The presence of mental capacity as a key cue for the banking and finance professionals is surprising, given that this did not emerge when finance professionals described incidents of elder financial abuse in the early stages of the research. Using mental capacity as a cue of elder financial abuse may be associated with knowledge regarding who is in control of the individual's finances. Capacity is linked with responsibility. Mental capacity may well be an accurate predictor as identified by Choi et al. (1999). The assets and ageing research programme reported that where older people are independently managing their money and have mental capacity to make financial decisions, there is less opportunity for financial abuse (Wilson et al., 2009).

\section{Limitations}

The methods of financial abuse developed in the early stages of the research reflected the types of abuse occurring at the time of the study. However, fraudsters' methods continually change and research has to keep pace with changes in perpetrators behaviours. It was also not possible to access financial institutions "fraud policies" to prepare the case scenarios due to these being protected documents, so there maybe relevant information which could be guiding professionals which have not been incorporated into the research design. However, this is unlikely as representatives from banking and finance organisations were members of the Project Advisory Committee and actively contribute to the design of the information included in the scenarios in order to make them as valid as possible. They supported the need for the project as they 
recognised that their members needed more detailed evidence based training in order to detect and prevent elder financial abuse.

\section{Implications}

The emphasis on the nature of the financial problem suspected has possible implications for the types of financial problems that and finance professionals are most likely to identify. Whilst it seems than professionals are attuned to certain types of financial problems such as well-known scams, cases involving small amounts of money being taken over of a long period of time may be less likely to be identified. Banking and finance professionals need to be aware of the range of ways in which elder financial abuse might present itself, as not all cases will involve large amounts of money.

With the expanding government policy which aims to give responsibility for personal budgets to those in receipt of care services, those who are most vulnerable in our society are likely to have more financial support from carers and family. Although this may give more autonomy to individuals in terms of how they spend their funding, it could put them at greater risk in terms of financial abuse (Social Care Institute for Excellence, City of London Police and National Fraud Intelligence Bureau, 2011). Prevalence of abuse rates will need to be carefully monitored to identify any increases in occurrences.

\section{Value}

The case scenarios and the identification of the key cues have been used to develop on-line training for novice finance professionals. The advisory board members have also kindly contributed "expert" podcasts discussing some of the case scenarios and effective methods for collaborative working. This freely available web training resource has been funded by the ESRC follow-on fund and is now available at www.elderfinancialabuse.co. uk; CIFAS and BSA e-bulletins have been used to endorse and circulate the research and training resource to hundreds of financial member organisations which they support. These evidenced based training resources will hopefully support banking and finance professionals to improve their ability to detect and prevent elder financial abuse and thereby protect older people from such abuse.

\section{References}

Alzheimer's Society (2011), Short Changed: Protecting People with Dementia from Financial Abuse, Alzheimer's Society, London.

Arksey, H., Corden, A., Glendinning, C. and Hirst, M. (2008), "Managing money in later life: help from relatives and friends”, Benefits: The Journal of Poverty \& Social Justice, Vol. 16 No. 1, pp. 47-59.

British Banking Association (2010), "Safeguarding vulnerable customers, banking best practice: advice for bank staff", available at: www.bba.org.uk/media/article/Fighting-fraud-keep ing-safe (accessed 22 September 2012).

Centre for Policy on Ageing (2008), The Financial Abuse of Older People, CPA Briefings, Centre for Policy on Ageing, London.

Choi, G., Kulick, D.B. and Mayer, J. (1999), "Financial exploitation of elders: analysis of risk factors based on county adult protective services data", Journal of Elder Abuse \& Neglect, Vol. 10 Nos 3/4, pp. 39-62.

CIFAS (2012), Fraudscape: Depiciting the UK's Fraud Landscape, available at: www.cifas.org.uk/ research_and_reports (accessed 22 September 2012).

\section{Financial abuse against elders}


JFC 21,1

98
Cooksey, R.W. (1996), Judgement Analysis: Theory, Methods, and Applications, Academic Press Limited, London.

Crosby, G., Clark, A., Hayes, R., Jones, K. and Lievesley, N. (2008), The Financial Abuse of Older People: A Review from the Literature, Help the Aged, London.

Davies, M., Harries, P., Cairns, D., Stanley, D., Gilhooly, M., Gilhooly, K., Notley, E., Gilbert, A., Penhale, B. and Hennessy, C. (2011), "Factors used in the detection of elder financial abuse: a judgement analysis and decision making study of social workers and their managers", International Social Work, Vol. 54 No. 3, pp. 404-420.

Deem, D. (2000), "Notes from the field: observations in working with the forgotten victims of personal financial crimes", Journal of Elder Abuse \& Neglect, Vol. 12 No. 2, pp. 33-48.

DH (2000), No Secrets: Guidance on Developing and Implementing Multi-Agency Policies and Procedures to Protect Vulnerable Adults from Abuse, Department of Health, London.

DH (2008), Safeguarding Adults: A Consultation on the Review of the "No Secrets" Guidance, Department of Health, London.

Dülmer, H. (2007), "Experimental plans in factorial surveys: random or quota design?", Sociological Methods \& Research, Vol. 35 No. 3, pp. 382-409.

Edmonds, J. and Noble, P. (2008), Responding to the Financial Abuse of Older People Understanding the Challenges Faced by the Banking and Financial Services Sector, Loddon Campaspe Community Legal Centre, Bendigo.

Fealy, G., Donnelly, N., Bergin, A., Treacy, M.P. and Phelan, A. (2012), Financial Abuse of Older People: A Review, NCPOP, University College Dublin, Dublin.

Field, A.P. (2009), Discovering Statistics Using SPSS (and Sex and Drugs and Rock " $n$ " Roll), Sage, London.

Flanagan, J.C. (1954), "The critical incident technique”, Psychological Bulletin, Vol. 51 No. 4, pp. 327-358.

Gilhooly, M., Cairns, D., Davies, M., Harries, P., Gilhooly, K. and Notley, E. (2013), "Framing the detection of financial elder abuse as bystander intervention: decision cues, pathways to detection and barriers to action", The Journal of Adult Protection, Vol. 15 No. 2, pp. 54-68.

Hardy, M.A. (1993), "Regression with dummy variables", Sage University Paper Series on Quantitative Applications in the Social Sciences, Series No. 07-093, Sage, Newbury Park, CA.

Kaye, A.P. and Darling, G. (2000), "Oregon's efforts to reduce elder financial exploitation”, Journal of Elder Abuse and Neglect, Vol. 12 No. 2, pp. 99-102.

Lowndes, G., Darzins, P., Wainer, J., Owada, K. and Mihaljic, T. (2009), Financial Abuse of Elders: A Review of the Evidence, Monash University, Melbourne.

Mulroy, M. and O'Neill, D. (2011), "Elder abuse: extends beyond health and social care to the financial and legal sectors", British Medical Journal, Vol. 343 No. 7827, pp. 756-757.

National Centre on Elder Abuse (1998), The National Elder Abuse Incidence Study: Final Report, The Administration for Children and Families and the Administration on Aging, Washington, DC.

Office of Governor (2009), "Governor Schwarzenegger highlights important legislation taking effect January 1", press release by Governor Arnold Schwarzenegger, available at: www. gov.ca.gov/index.php?/press-release/1129/ (accessed 5 April 2011).

O’Keefe, M., Hills, A., Doyle, M., McCreadie, C., Scholes, S., Constantine, R., Tinker, A., Manthorpe, J., Biggs, S. and Erens, B. (2007), Prevalence Survey Report, UK Study of Abuse and Neglect of Older People, Research Findings, King's College and National Centre for Social Research, London. 
Rossi, P.H. and Nock, S.L. (1982), "The factorial survey approach: an introduction", in Rossi, P.H. and Nock, S.L. (Eds), Measuring Social Judgments: The Factorial Survey Approach, Sage, Beverly Hills, CA, pp. 15-67.

Social Care Institute for Excellence, City of London Police and National Fraud Intelligence Bureau (2011), Assessment: Financial Crime Against Vulnerable Adults, Report 49, Adults' Services SCIE, London.

Taylor, B.J. (2006), "Factorial surveys: using vignettes to study professional judgement", British Journal of Social Work, Vol. 36 No. 7, pp. 1187-1207.

Wilson, J., Tilse, C., Setterlund, D. and Rosenman, L. (2009), "Older people and their assets: a range of roles and issues for social workers", Australian Social Work, Vol. 62 No. 2, pp. 155-167.

\section{About the authors}

Dr Priscilla A. Harries is a Senior Lecturer and Chair of the Editorial Board of the British Journal of Occupational Therapy. Priscilla A. Harries is the corresponding author and can be contacted at: priscilla.harries@brunel.ac.uk

Dr Miranda L. Davies is a postdoctoral Research Fellow.

Professor Kenneth J. Gilhooly is a Professor of Psychology.

Mary L.M. Gilhooly is a Deputy Head of Research for the School of Health Sciences and Social Care and Executive Director, Brunel Institute for Ageing Studies.

Dr Deborah Cairns is a Senior Research Fellow.

\section{Financial abuse against elders}

99

To purchase reprints of this article please e-mail: reprints@emeraldinsight.com Or visit our web site for further details: www.emeraldinsight.com/reprints 